\section{THE INTERNATIONAL CHEMICAL CONGRESS.}

$A \mathrm{~N}$ International Chemical Congress has just been held in Paris under the presidency of M. Berthelot. The Congress was composed of some 300 members, including the most eminent French chemists, and a certain number of distinguished foreigners. It was much regretted that foreign countries should not have been more numerously represented, and it was explained that owing to the protracted illness of M. Hanriot, Secretary of the Paris Chemical Society and of the Congress, the invitations were not sent out till very late, and still further delay was caused by their passage through the Ministry of Public Instruction. Much credit is due to M. Fauconnier, who undertook to replace M. Hanriot at the last moment.

The opening meeting was held on the 29th ult. at the Conservatoire des Arts et Métiers, the proceedings being of a purely formal character. M. Berthelot, who occupied the chair, said that a large number of communications had been received by the organizing Committee, and that from the nature of these communications it had been found expedient to divide the Congress into four Sections, which he proceeded to enumerate, together with the list of Sectional Presidents and Secretaries proposed by the Committee :-

Section I. Analysis of Food-Products: President, M. Riche; Secretary, M. Bishop.

Section II. Analysis of Agricultural Products: President, M. Joulie; Secretary, M. Demoussy.

Section III. Analysis of Pharmaceutical Products: President, M. Petit ; Secretary, M. Bocquillon.

Section IV. Unification of Chemical Nomenclature : President, M. Friedel ; Secretary, M. Bouveault.

The Sectional meetings took place in the day-time; the evenings of July 30 , August I, 2, and 3 , being reserved for the discussion of the reports presented by the various Sections.

Section I.-The Section discussed a certain number of methods used in the analysis of flour, bread, wine, coffee, \&c. At the general meeting the following resolutions were passed :-

(I) That the Government be requested to inspect regularly the factories of salted meats, as at present the brines used are added to constantly, but never changed (report by M. Combes).

(2) That the Government be requested to inspect all teas on their entry into France.

(3) That not more than $0^{\circ} 3$ per cent. of lead should be permitted in the alloy used for "tinning," nor more than 5 per cent. in the alloy for tin vessels.

(4) That it is desirable that the methods of wine analysis should be verified and codified.

Section II.-After discussion of the methods at present in use for the analysis of earths, manures, \&c., it was resolved that in the case of judicial disputes no single method should in any case be obligatory, ${ }^{1}$ but that the fullest latitude should be allowed to the experts.

Section III.-It was resolved that a certain number of permanent Commissions should be appointed for the inspection of some of the most important substances used in pharmacy -quinine, morphine, chloroform, phenol, salicylic acid, analgesine, \&c. The Commissions should endeavour to investigate and improve the methods of analysis used for these substances.

Section IV.-Section IV. was the one of by far the greatest general interest, as was testified by the presence of Profs. Alexeieff (Kiew), Calderon (Madrid), Franchimont (Leyden), Graebe (Geneva), Istrati (Bucharest), Noelting (Mulhouse), Boukowski Bey (Constantinople), and Colonel da Luz (Rio Janeiro), who were elected VicePresidents.

r The Comite Consultatif des Stations Agronomiques et des Laboratoires Agricoles has issued a code of the methods of analysis of manures, and these are at present obligatory.
The following is a short account of the discussions held at the Sectional meetings :-

The Nomenclature of Unsaturated Hydrocarbons.M. Calderon read a paper, in which he proposed to replace the present arbitrary names of the hydrocarbons by a series of names derived from the fundamental terms of each series. He proposes to name paraffins, protomethane, deuto-methane, \&c., the olefines deuto-ethylene, trito-ethylene, \&x. The radicles are derived from the hydrocarbons by the insertion of Latin numerals between the Greek numeral and the generic name; thus, methyl becomes proto-uni-methane, \&c. The author advocated these changes as calculated to facilitate the teaching of organic chemistry.-MM. Friedel, Grimaux, Graebe, and Maquenne expressed the view that it was impossible to make changes so radical, and that Hofmann's nomenclature was quite sufficient so far as the normal hydrocarbons are concerned.

M. Béhal presented a report to the Section on a system for the nomenclature of complex open-chain compounds. He regards them as formed by the addition of characteristic groups (groupements fonctionnels), ${ }^{1}$ in which certain atoms of hydrogen are replaced by various radicles. These radicles are given in the order of the number of carbon atoms they contain, starting with the lowest. To denote different isomars the Greek letters, $a, \beta, \gamma, \delta$, are employed. One or two examples may be given. The body

$$
\mathrm{CH}_{3}-\mathrm{CO}-\mathrm{C} \equiv \mathrm{C}-\mathrm{CH}_{2}-\mathrm{CHO}
$$

would be called acetyl-acetylene-ethaldehyde (acétylacétylène aldéhyde éthylique). The body

$$
\underset{\mathrm{CH}_{3}-\mathrm{CO}}{\mathrm{CH}_{3}-\mathrm{CH}_{2}-\mathrm{CO}}>\mathrm{C}=\mathrm{C}=\mathrm{C}<{ }_{\mathrm{CH}_{3}}^{\mathrm{COOH}}
$$

would be called acetyl propionyl allene" methyl formic acid.-Many objections were raised to M. Béhal's proposition by MM. Friedel, Graebe, Grimaux, and others, and it was finally decided to refer it to the Permanent Committee.

Derivatives of Ethylene and Urea.-M. Graebe proposed to denote the two atoms of carbon in ethylene derivatives, united by the double bond, by the letters $a$ and $b$. If two similar radicles are introduced into the ethylene molecule, as, for example, in dimethyl ethylene, the two isomers would be called ab.dimethyl ethylene and dimethyl ethylene, or for greater clearness $a$-dimethyl ethylene. In the case of trisubstituted compounds it should be understood that the first two radicles were linked to the same carbon atom.-M. Franchimont proposed to adopt the same nomenclature for the urea derivatives. -Attention was drawn to the possibility of new isomers, if Wislicenus's extension of the Van 't Hoff-Lebel hypothesis should be proved to be of general application, but it was decided for the present not to number the four atoms of hydrogen in ethylene, and M. Graebe's proposition and M. Franchimont's rider were adopted.

Aldehydes.-M. Grimaux proposed a resolution recommending that in future aldehydes should be named after the corresponding alcohols, and not after the acids. $\mathrm{He}$ pointed out that this usage was consistent with the etymological origin of the word, and that the practice of giving the same name to alcohols and their corresponding acids would give rise to confusion in the names of the acid and hydrocarbon radicles which they contain; the names corresponding to ethyl and acetyl, to benzyl and benzoyl, would become identical if we used the names

I In France the word function is used in the following sense. Methyl alcohol gives rise by substitution to compounds whose chemical behaviour is similar to its own, and are therefore said to have the same chemical finction. The group $\mathrm{CH}_{2} . \mathrm{OH}$ is thus characteristic of the primary alcohol function; similarly, the group $\mathrm{C}=\mathrm{C}$ of the ethylene function, the group

$\mathrm{H} . \mathrm{C}=\mathrm{O}$ of the aldehyde function, \&c., \&c.
2 Or isoallylene. 
ethylic alcohol, ethylic acid, benzoic alcohol, benzoic acid. -M. Grimaux's proposition was adopted.

The Use of the Prefixes bi- and di-.-M. Bouveault proposed, in the name of M. Hanriot, that the prefix bi should be reserved for the denomination of bodies formed by the duplication of organic radicles; the words dipropargyl, diphenyl, dinaphthyl to be replaced by bipropargyl, biphenyl, binaphthyl. ${ }^{1}$ M. Maquenne preferred to use $d i$ instead of bi for these double radicles; but it was pointed out that there were only about twelve bodies whose names would need to be changed to be in harmony with M. Hanriot's proposition, whereas the converse proposition would be much more difficult of adoption. M. Grimaux thought that in any case it would be difficult to alter existing nomenclature at once, but proposed that the Congress should express a wish that M. Hanriot's system of nomenclature should be adopted for all new bodies, and should gradually replace the existing one.-M. Grimaux's modification of M. Hanriot's proposition was adopted.

The Use of the Suffix-ol.-M. Grimaux proposed that the suffix -ol should be restricted as far as possible to the alcohols, and that the names of all hydrocarbons should contain the letter $n$. He proposed that the ending -ene employed by English chemists, should be made use of for the aromatic hydrocarbons. Bensine and naphtaline in French, benzol in German, would be replaced by the English terms benzene and naphthalene.-M. Graebe warmly supported this proposition, and further suggested the abbreviation of naphthalene to naphthene.-M. Grimaux's proposition was adopted.

Ketones.-M. Friedel pointed out the ambiguity which exists in the French nomenclature of the acetones. Dimethyl acetone might mean either the body $\mathrm{CO}\left(\mathrm{CH}_{3}\right)_{2}$ or else $\mathrm{CH}_{3}-\mathrm{CH}_{2}-\mathrm{CO}-\mathrm{CH}_{2}-\mathrm{CH}_{3}$ (or its isomer). He proposed to adopt the German notation for these bodies, and in general to replace the word carbonyl by the word cetone (this form being more adapted to the French language than ketone). Dimethyl cetone is then ordinary acetone. - The proposition was adopted.

The Group - C EN.-M. Bouveault proposed to name this group carbazit.-M. Calderon and other members of the Congress were in favour of this name. It was also proposed to use the word nitrile universally.-M. Grimaux then pointed out that, as we made no distinction of nomenclature between the molecule and the half-molecule of chlorine, it would be unnecessary to do so in the case of cyanogen, and he proposed that the group $-\mathrm{C} \equiv \mathrm{N}$ be denoted by the name cyanogen.- M. Grimaux's proposition was adopted.

The Sulphur Compounds.-M. Chabrié read a report on the sulphur compounds. He complained that a certain number of chemists used the term sulphine for compounds containing no oxygen, and which should properly be termed sulphides. He proposed that the name sulphine should be reserved for compounds of the formula $(\mathrm{SO}) \mathrm{R}_{2}$, sulphones for compounds $\left(\mathrm{S}_{(}{ }_{2}\right) \mathrm{R}_{2}$, derived respectively from sulphurous and sulphuric acids. This nomenclature is used by Beilstein in his invaluable compilation. It is naturally applicable to corresponding selenium and tellurium compounds. - It was decided to refer M. Chabrié's report to the Permanent Committee.

Ring Formule containing Nitrogen. - M. Bouveault read a long report on the subject. He proposed to adopt Widmann's nomenclature, with certain modifications in the details.-A protracted discussion ensued, and finally M. Graebe proposed that M. Bouveault's report should be frinted and widely distributed, so as to elicit the opinion of all the chemists who had specially devoted

${ }^{x}$ It may be mentioned that whereas in England the use of the prefix bihas been almost entirely aband ned, in France it is still employed, though no rules for its use have hitherto been given; the terms di-nitro benaine and benzine bi-nitré denote the same body. themselves to the study of these compounds, and this was agreed to. ${ }^{1}$

Naphthalene.--M. Noelting read a report on the nomenclature of the naphthalene derivatives. He began by describing the various notations of Beilstein, Graebe and Noelting, Meldola, Weinberg, and the Swedish chemists. He proposed to denote the carbon atoms of the naphthalene ring by figures and to extend this system to anthracene, phenanthrene, \&c. M. Noelting's proposal was adopted after discussion. The figures will be found below in the summary of the resolutions of the Congress. -It was agreed, on the suggestion of $M$. Auger, that when it was known that the radicles of a given di-substituted compound were in different rings, but their exact position was uncertain, they should be denoted by the symbol $\mathrm{AB}$.

Benzene-M. Combes read a report on the numeration of substituted benzene derivatives. He proposed to assign the place (I) to the hydrocarbon radicle containing the smallest number of atoms of carbon : in the absence of a hydrocarbon radicle he proposed to begin with the group having the lowest "molecular weight."--M. Combes gave as the reason for choosing the simplest hydrocarbon for the position (I) that it was this one which was gener. ally attacked last by oxidizing agents.

$M$. Alexeieff pointed out that the oxidation of paracymene, $\mathrm{C}_{6} \mathrm{H}_{4} \cdot \mathrm{CH}_{3} \cdot \mathrm{C}_{3} \mathrm{H}_{7}$, by the action of air and caustic soda, gives rise to cuminic acid, $\mathrm{C}_{6} \mathrm{H}_{4} \cdot \mathrm{CO}_{2} \mathrm{H} . \mathrm{C}_{3} \mathrm{H}_{7}$, and that in this case the position (I) would bechanged, although there was no transposition in the molecule. ${ }^{2}$

M. Combe's report was referred to the Permanent Committee.

The general meeting for the discussion of the report of Section IV. was held under the presidency of M. Friedel, in the absence of M. Berthelot.

The following resolutions were adopted:-

(I) That an International Committee, with power to add to its number, be formed, whose object shall be to promote uniformity of chemical nomenclature.

The following gentlemen were nominated to serve on the Paris Committee :-MM. Berthelot, Friedel, Gautier, Grimaux, Jungfleisch, Bćhal, Bouveault, Combes, Fauconnier.

That the Committee shall immediately request the following gentlemen to join them:-M.M. Alexeieff (Russia), Armstrong (England), Baeycr (Germany), Beilstein (Russia), Boukowski Bey (Turkey), Calderon (Spain), Clève (Scandinavia), Franchimont (Holland), Graebe (Switzerland), Istrati (Roumania), Lieben (Austria-Hungary), Noelting (Germany), Paternò (Italy), Ira Remsen (United States).

(2) The two carbon atoms in ethylene, and the two hydrogen atoms in urea, shall be distinguished by the letters $a$ and $b$ (proposed by MM. Graebe and Franchimont).

(3) The aldebydes shall be named after their corresponding alcohols (proposed by M. Grimaux).

(4) The word carbonyl shall be replaced by the word cetone ${ }^{3}$ (proposed by M. Friedel).

(5) The group - $\mathrm{C} \equiv \mathrm{N}$ in organic compounds shall be called cyanogen, instead of nitrile (proposed by M. Grimaux).

(6) The suffix -ol shall be reserved as far as possible for alcohols. In the hydrocarbons it is to be replaced by the ending -ene (proposed by M. Grimaux).

(7) The prefix bi-shall in future be reserved for bodies formed by the union of two radicles such as biphenyl $\left(\mathrm{C}_{6} \mathrm{H}_{5}\right)_{2}$, bipropargyl $\left(\mathrm{C}_{3} \mathrm{H}_{3}\right)_{2}$, and the Congress expresses

I The nomerclature of the pyridice and quinoleine derivatives agreed to by the Section was afterwards referred back to the Committee.

Cince the xidation of paracymene by chromic acid gives rise to paratuluic acid. 3 ' This applies only to French nomenclature. 
the desire that this nomenclature may be gradually adopted for bodies already known; the prefix $d i$ - to be used as at present, to denote bodies formed by double substitution (proposed by M. Hanriot).

(8) The different carbon atoms of naphthalene anthracene, phenanthrene, fluorene, carbazol, acenaphthene, acridine, shall be numbered as follows:-
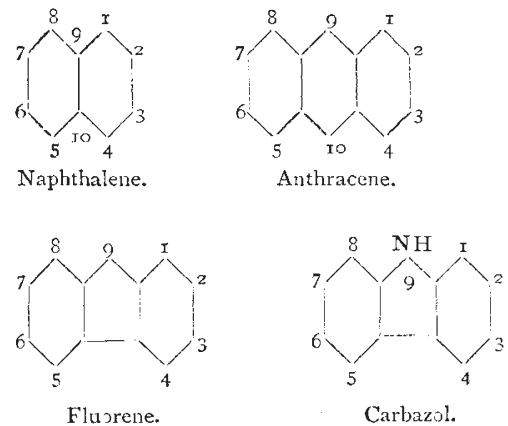

(Proposed by M. Noelting.)

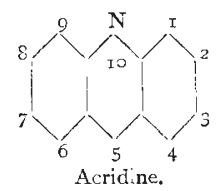

(9) The proposition to denote the carbon atoms of quinolcine by $a, \beta, \gamma$ for the pyridine ring, and $a, m, p, a$ (ortho, meta, para, ana) in the benzine ring, ${ }^{3}$ which had been voted at the Sectional meeting, was adjourned by a vote of 42 against 26 , and referred to the Permanent Committee.

After the carrying of the resolutions, M. Friedel made a short speech. in which he thanked especially the foreign members for their attendance and help. Some people might, he said, think that the Section had accomplished but little ; that, however, was not his opinion : their aim had been to help workers in their work, and nothing could be more conducive to this aim than the use of the same language among the chemists of all countries. He felt sure that their efforts would prove fruitful in the future, and he hoped that by next year the International Committee would be able to report such serious progress as to justify the summoning of another Congress.

Thus terminated the formal proceedings of the Section and Congress, which had been marked throughout by the greatest good feeling among the sazrants of the various nations represented. On Sunday the Congress was brought to a final close by a banquet offered to the foreign members at the Terminus Hotel.

\section{THE REV. M. J. BERKELEY.}

$$
\mathrm{T}^{\mathrm{H}}
$$
HE death of our great English mycologist has followed very close upon that of our great English lichenologist. Both of them were country clergymen of the Church of England, both were over eighty, and the career of both as botanical authors has extended over half a century.

The Rev. Myles Joseph Berkeley, M.A, F.R.S., was born at Biggin, in the parish of Oundle, in the year I 803 . He was a descendant of the old historic family of that name. He was educated at Rugby, and at Christ's College, Cambridge, and graduated as fifth Senior Optime in the year 1825. After holding a curacy at Margate, he was appointed, in 1833 , incumbent of two small parishes near Wansford, in his native county. Here he remained for thirty-five years, actively engaged in the performance of his parochial work. His stipend was s nall and his family large, and he had to supplement his clerical income by taking private pupils. This of course absorbed a great deal of his leisure, but his industry and force of character were so great that he got through, in addition, an enormous amount of scientific work. In 1868 he was appointed to the more valuable living of Sibbertoft, near Market Harborough, which he held until his death, on July 3o. During the last ten years his he.1th has failed, and in 1879 he presented his botanical collections to Kew, and, since that time, has published scarcely anything.

His attachment to botany must have begun very early in life, for I remember him saying, when we were speaking about a certain botanical examination, that he had not set any questions that he could not have answered when he was six years old. His friends thought he would have taken a higher degree at Cambridge if he had not given so much attention to natural history. His first book, "Gleanings of British Algæ," appeared in 1833 . It deals mainly with minute microscopic types. The book which made his reputation was his "Monograph of the Britis' Fungi," which forms the third volume of Hooker's "British Flora," published in 1836 This was the only hand-book of the British species in existence up to I 871 , so that for thirty-five years it was the indispensable companion of every worker. The "Systema Mycologicum" of Fries, which summarized most ably all that was then known about genera and species, came out -the three volumes from I 82 I to I 829 , its "Supplement" in 1830 . and the "Elenchus" in 1828 ; so that these were just in time to serve Berkeley as a foundation to build upon. From 1836 to 1870 he was the universal referee for everyone in this country who wanted information about fungi. Collections poured in upon him from home and abroad, and he described many thousands of genera and species, a large proportion of which were new, in Hooker's "Antarctic Floras," Hooker's Journals of Botany, the Transactions and Journal of the Linnean Society, and in the Annals of Natural History. During the latter part of the time he worked a great deal in conjunction with the late Mr. C. E. Broome, of Bath, who had abundant leisure and industry, combined with an unconquerable disinclination to publish on his own account, and in every Fungus-list "Berk. et Broome" is an often-quoted authority. Beginning with Oidium Tuckeri, he gave special attention to the fungoid pests of agriculture and horticulture; and it was, more than anything else, his papers on the potato disease that obtained for him the small pension that was granted to him during the last twenty years of his life. In 1857 he published a general "Introduction to Cryptogamic Botany," which has had a wide circulation. There has been no other book of a similar scope in the English language till this present year. His "Outlines of British Fungology," published in I860, contains twenty-four plates, illustrating a series of about 150 typical forms. The text deals specially with the Hymenomycetes, and, for the other orders, does not go much beyond a catalogue of the British genera and species. His "Hand-book of the British Mosses," published in 1863 , contains descriptions and plates of all the species then known in Britain. In the same year he was awarded the Biological Gold Medal of the Royal Society, of which he was elected a Fellow in 1879 . But by this time his working days were over, and in that year he presented to Kew his entire fungus herbarium, followed, not long after, by his books. His herbarium contains specimens of upwards of ro,oco species, duly named and classified; and it has be $€ n$ estimated by Mr. G. E. Massee that it contains type specimens of 4866 species described by himself, and that the full number of new species which he described will not fall far short of 6000 .

For many years he acted as one of the botanical exa- 